\title{
Evaluation of Direct Seeded Rice Planter under Minimum Tillage Practices
}

\author{
A. K. M. S. $\operatorname{Islam}^{1} *$, M. M. Hossain ${ }^{2}$ and M. A. Saleque ${ }^{1}$ \\ ${ }^{1}$ Bangladesh Rice Research Institute, Gazipur, Bangladesh \\ ${ }^{2}$ Bangladesh Agricultural University, Mymensingh, Bangladesh \\ *Corresponding author and Email: akmsaifulislam68@gmail.com
}

Received: 06 July $2012 \quad$ Accepted: 06 December 2013

\begin{abstract}
This experiment was conducted in the farmer's field to evaluate the performance of a modified planter machine for establishing direct seeded rice during aman and aus seasons in 2010 with four tillage treatments: (i) conventional tillage (CT) (ii) strip tillage (ST), (iii) bed formation (BP) and (iv) zero tillage (ZT). In later three treatments, seeding and fertilizer application was done simultaneously in a single pass operation by the planter. Flute type seed metering device was tested to study the seed dispensing rate, placement of seed and fertilizers. Minimum tillage saved fuel consumption by almost $25-46 \%$ and could represent a $27-48 \%$ cost saving in land preparation compared to CT. In addition to fuel savings, substantial time savings and additional benefits can be achieved. Seedling emergence was not affected by tillage options which indicated that seeds were placed at proper depth. Seed meter worked well to dispense rice seeds by maintaining actual seed rate. Seeds were not broken due to use of flute type seed metering device. Yields were not significantly different among the tillage treatments. $\mathrm{BP}$ showed the lowest benefit-cost ratio due to higher input cost as well as gross margin was lower compared to other tillage treatments. Strip tillage performed better than the other two minimum tillage methods compared to conventional method. Planter reduced seeding time, saved fuel and labour costs compared to conventional method and helped in timely sowing. Minimum tillage may be adopted to establish dry seeded rice in High Barind Tract.
\end{abstract}

Keywords: Fuel consumption, labour, seedling emergence, weeding, yield, cost

\section{Introduction}

Dry direct seeding has been the principal method of rice establishment since the 1950s in the developing countries (Pandey and Velasco, 2005). In Bangladesh, after harvesting aman rice, lands dries at a faster rate leaving very short turnaround time for land preparation for the next rabi crop. Reduced tillage practices can be useful after aman rice harvest in areas of high water scarcity (Rashid and Islam, 2007). Rice seed can be broadcasted after ploughing, following only $150 \mathrm{~mm}$ of cumulative rainfall (Saleh and
Bhuiyan, 1995). Earlier planted Direct Seeded Rice (DSR) matures 1-2 weeks before transplanted rice, thus reducing the risk of terminal drought and allowing earlier planting of a following non-rice crop (Saleh et al., 2000). Kukal and Aggarwal (2002) mentioned that both direct seeding (viz. wet, dry or water seeding) and transplanting had similar yield. DSR offers several potential benefits as it uses less water with high efficiency, incurs low labour expenses and is conducive to mechanization (Bhuiyan $e t$ al., 1995). Despite these benefits, there are several constraints in DSR such as weed 
infestation, poor crop establishment, lodging and lower grain yield. Among these issues, poor seedling stand has been considered as the most important one due to bird damage, uneven sowing depth, seed dryness and buoyance of seed. Farmers use high seed rate because of poor plant stand and severe weed infestation in broadcasted DSR fields (Pathinayake et al., 1990). Timely sowing i.e., sowing a week before the onset of monsoon rain may improve germination and plant stand of aman rice (Kathiresan et al., 1997). At present, 23\% of rice is direct-seeded globally (Rao et al., 2007).

Conventional tillage and hand broadcasting of seeds is a laborious and time-consuming operation. Machine sowing permits crops to take advantage of residual moisture in crop fields. Many machines have been developed in ricegrowing countries and international institutes suitable for DSR. For the small farm holders, the Versatile multi-crop planter (VMP) was developed to overcome some of the DSR constraints (Islam et al., 2010 and Haque et al., 2011). Rickman et al. (1999) reported that crop lodging is a significant problem in dry seeded rice in Cambodia, particularly with traditional varieties with full conventional tillage systems but machine drilling of seeds could reduce lodging to less than $10 \%$. Chinese scientists have developed a two-wheel tractor operated seeder that provides tillage, seeding and leveling in one operation (Hobbs et al., 1997). The main components were shallow rotovator, six-row seeding system and soil compaction roller. Bell et al. (1999) evaluated several commercial seeder systems for reduced and zero-tillage seeding of rice, including the Chinese seeder, and reported that rice seed flow was a problem for the tractor-mounted seeders. Residue management was difficult for the tyne based no tillage systems, as none of the seeders had trash cutters. Many of the seeders required a welllevelled and relatively clean surface to work properly.

The recent economic and environmental impacts have compelled the farming community to reconsider the use of tillage operations and implement alternative technologies for soil cultivation. Minimum tillage technologies are now gaining popularity throughout the world to save time in field preparation and reduce inputs. The labour input, energy input, capacity and costs are different for each of these systems. The present study was undertaken to evaluate the seed metering device of the planter and to evaluate the agronomic performance of direct seeded rice in line sowing under different tillage systems and fertilizer application in single pass operation using the planter.

\section{Materials and Methods}

\subsection{Experimental design and treatments}

The experiment was conducted in the farmer's field, Godagari, Rajshahi during aus season (2010) and aman season (2010). The soil was silty clay in High Barind Tract, Rajshahi. The treatments were: i) conventional tillage (CT); ii) strip tillage (ST); iii) bed planting (BP); and iv) zero tillage (ZT). The experiment was conducted in a randomized complete block (RCB) design with three replications.

\subsection{Crop establishment and husbandry}

In aus season, BRRI dhan42 was sowed on 24 April, 2010 and harvested on 7 August, 2010. In aman season, BR 11 was sowed on 17 June, 2010 and harvested on 12 November, 2010. Before seeding, flute type seed meters were calibrated for each treatment to get the recommended and uniform seed rate. Seeds were poured into the hopper. In each trial, sample was collected from the seed dispensing tube in polythene bag from 10 revolution of drive wheel. Sample seeds were spread on a sheet to count the damaged seeds and taken weight. Uniform seed rate in each flute type seed meter was maintained by adjusting gap of seed meter. Seed adjusting level was placed in such a position to get recommended rate. 
Fuel consumption was measured by filling the fuel tank twice, before and after each operation. Re-filled volume was the actual fuel consumption. In CT, land was prepared with two passes tillage by $2 \mathrm{WT}$ followed by leveling. Seeds and fertilizer were hand broadcast in CT. In ST, BP and ZT, land preparation, seeding and basal fertilizer application were done simultaneously in single pass operation by the planter. In BP, the width of bed and furrow were $38 \mathrm{~cm}$ (top) and $20 \mathrm{~cm}$, respectively. Row to row spacing in CT, ST, BP and ZT were 25, 20, 25 and $20 \mathrm{~cm}$, respectively. The amount of human labour involved in each operation was investigated through field measurements.

In aus season, rice was grown after harvesting potato. Farmers usually used excess fertilizers in potato cultivation. Farmers did not apply basal or top dressed fertilizer after potato cultivation to grow aus rice. In aman season, fertilizers were applied at 175, 80, 110, 100 and $10 \mathrm{~kg} \mathrm{ha}^{-1}$ as urea, triple super phosphate (TSP), muriate of potash (MP), gypsum and zinc sulphate, respectively. In aus season, land was irrigated at night and excess water was drained out in the morning due to high ambient temperature. Irrigations were applied as and when required uniformly in all plots. In both seasons, irrigation water was applied five times in all the plots. In aman season, non-selective herbicide glyphosate was applied @ $7.51 \mathrm{ha}^{-1}$ one day before seeding in all the plots. In aus season, pre-planting herbicide was not used and the weed infestation was severe in all plots. Hand weeding was done on 26 days after seeding (DAS) to keep the field weed free. During aman season, weed infestation was less due to application of pre-planting herbicide. In addition, hand weeding was done twice at 35 and 60 DAS.

\subsection{Measurements and analysis}

Number of tillers in the selected area was counted at each growth stage. Tiller mortality was calculated based on successive tiller count data.
Grain yield was recorded from pre-selected 10 $\mathrm{m}^{2}$ area and was adjusted to $14 \%$ moisture content. A simple economic analysis was done based on total production.

\subsection{Economics}

Production cost included rental charge of the land and input cost. Price of the produce was collected from the local markets to compute total production cost, gross return, gross margin and benefit-cost ratio.

\subsection{Statistical analysis}

Statistical analysis as a one way analysis of variance was done according to Gomez and Gomez (1984). Data were analysed using statistical software Mstat-C. Means were compared with least significant difference (LSD) test.

\section{Results and Discussion}

\subsection{Fuel consumption}

Fuel consumption varied significantly among the tillage options (Table 1). Fuel consumption was found to be the highest in CT due to two passes of tillage operation and the lowest was by ST, followed by ZT and BP. ST saved (25-46\%) fuel in seeding operation compared with CT.

\subsection{Labour requirement in land preparation and seeding}

Tillage treatments showed significant differences in labour requirement for land preparation and seeding (Table 1). In both seasons, CT showed the highest labour requirement in land preparation. Labour requirement in land preparation was at par between BP and ZT in aus season, whereas in aman season, labour requirement was similar in $\mathrm{ST}$ and $\mathrm{ZT}$. Labour requirements for seed sowing by planter was decreased by $37-55 \%$ compared to hand broadcasting. 
Table 1. Tillage effect on fuel consumption, labour requirement and cost in land preparation

\begin{tabular}{|c|c|c|c|c|c|}
\hline Parameter & Treatment & Aus & Aman & Mean & $\begin{array}{c}\text { Percent decrease } \\
\text { relative to } \mathrm{CT}\end{array}$ \\
\hline \multirow{6}{*}{$\begin{array}{l}\text { Fuel consumption } \\
\left(1 \mathrm{ha}^{-1}\right)\end{array}$} & CT & 21 & 36 & 29 & - \\
\hline & ST & 10 & 21 & 16 & 46 \\
\hline & BP & 15 & 28 & 22 & 25 \\
\hline & $\mathrm{ZT}$ & 12 & 24 & 18 & 37 \\
\hline & $\mathrm{CV}, \%$ & 11 & 14 & & \\
\hline & $\mathrm{LSD}_{0.05}$ & 3.2 & 7.6 & & \\
\hline \multirow{6}{*}{$\begin{array}{l}\text { Labour requirement in land } \\
\text { preparation and seeding } \\
\left(\mathrm{man}-\mathrm{hr} \mathrm{ha}^{-1}\right)\end{array}$} & CT & 25 & 48 & 37 & - \\
\hline & ST & 15 & 18 & 17 & 55 \\
\hline & BP & 20 & 26 & 23 & 37 \\
\hline & $\mathrm{ZT}$ & 20 & 18 & 19 & 48 \\
\hline & $\mathrm{CV}, \%$ & 8.2 & 11.9 & & \\
\hline & $\mathrm{LSD}_{0.05}$ & 3.3 & 6.5 & & \\
\hline \multirow{6}{*}{$\begin{array}{l}\text { Land preparation and } \\
\text { seeding cost } \\
\left(\mathrm{Tk} \mathrm{hr}{ }^{-1}\right)\end{array}$} & $\mathrm{CT}$ & 1629 & 2975 & 2302 & - \\
\hline & ST & 921 & 1468 & 1195 & 48 \\
\hline & BP & 1303 & 2050 & 1677 & 27 \\
\hline & $\mathrm{ZT}$ & 1149 & 1624 & 1387 & 40 \\
\hline & $\mathrm{CV}, \%$ & 8.5 & 9.9 & & \\
\hline & $\mathrm{LSD}_{0.05}$ & 212. & 401 & & \\
\hline
\end{tabular}

N.B. Values are the means of three replicates

\subsection{Land preparation and seeding cost}

Tillage treatment showed significant effect on land preparation and seeding cost (Table 1). For both the seasons, land preparation cost was the highest in case of CT and the lowest in ST. ST incurred the lowest cost due to its single pass operation; seeding, fertilizing, and leveling simultaneously that decreased upto $27-48 \%$ cost compared to CT.

\subsection{Seedling emergence}

Figures 1 and 2 showed the emergence of seedling from direct seeded rice under different tillage options at 12-18 days after seeding (DAS). Similar seed rates were used in both seasons. Seedlings started to emerge on 12 and 13 DAS in all tillage treatment during aus and aman season, respectively. Tillage treatments had no significant effect on seedling emergence at different DAS.

\subsection{Tillering pattern}

The effect of tillage on tillering pattern of direct seeded rice is shown in Figures 3 and 4. Tillage treatment significantly influenced the plant population throughout the crop cycle in both season except at maturity stage in aus season. In both seasons, CT produced $10-40 \%$ more tillers than other treatments. At maturity stage, tillage options showed significant effect on tiller production in aus season. However, tillage options did not show significant effect on tiller production in aman season (Table 2).

\subsection{Panicle density}

Table 2 showed that tillage treatments did not have significant effect on panicle density, although $\mathrm{CT}$ produced the maximum number of panicles in both seasons. In aus season, although tillage treatment showed significant effect on plant population at maturity stage, panicle intensity was not affected due to variation in the number of non-bearing tillers. The lowest number of panicles was observed in BP $\left(292 \mathrm{~m}^{-2}\right)$ and ST $\left(219 \mathrm{~m}^{-2}\right)$ in aus and aman season, respectively. 


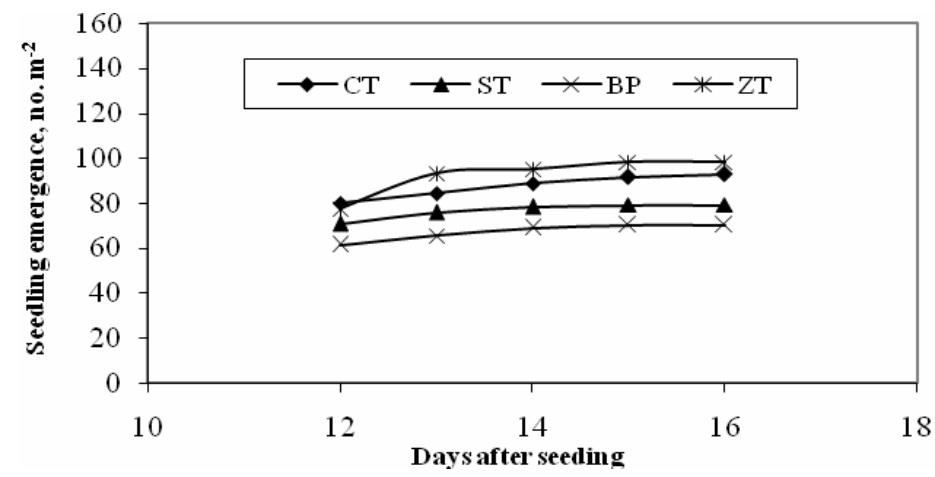

Fig. 1. Effect of tillage on seedling emergence of aus rice

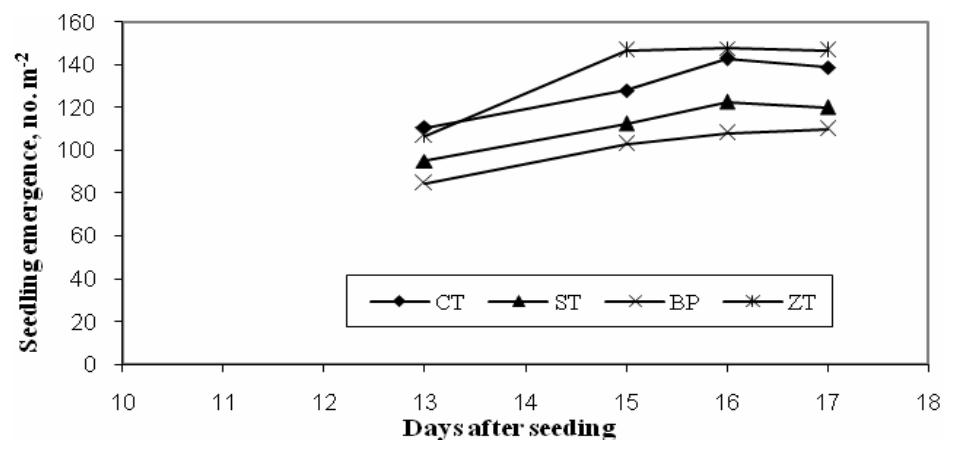

Fig. 2. Effect of tillage on seedling emergence of aman rice

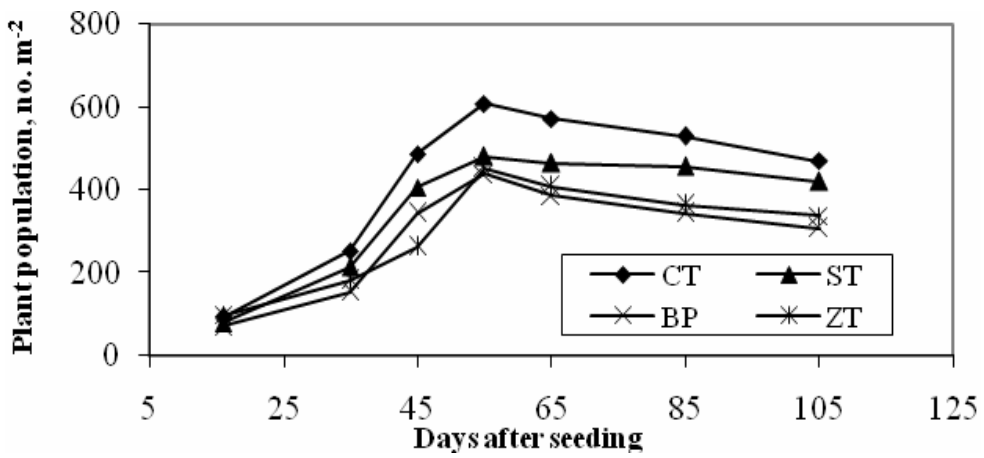

Fig. 3. Effect of tillage on tiller production of aus rice 


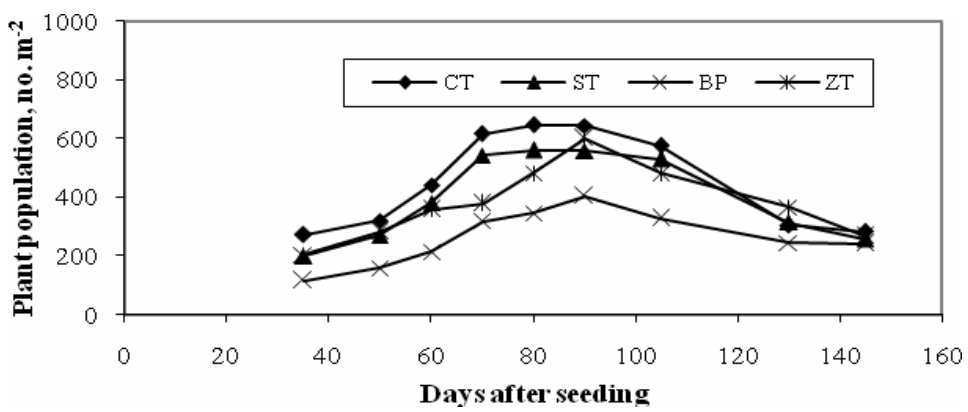

Fig. 4. Effect of tillage on tiller production of aman rice

Table 2. Yield contributing character of direct seeded rice

\begin{tabular}{lcccc}
\hline Treatment & \multicolumn{2}{c}{ Number of tiller $\left(\mathrm{m}^{-2}\right)$} & \multicolumn{2}{c}{ Number of panicle $\left(\mathrm{m}^{-2}\right)$} \\
\cline { 2 - 5 } & Aus & Aman & Aus & Aman \\
\hline CT & 469 & 283 & 345 & 260 \\
ST & 420 & 258 & 334 & 219 \\
BP & 308 & 243 & 292 & 221 \\
ZT & 338 & 268 & 315 & 238 \\
CV $(\%)$ & 12.7 & 17.2 & 13.8 & 20.5 \\
LSD & NS & 97 & NS & NS
\end{tabular}

N.B. Values are the means of three replicates

Table 3. Grain and straw yields

\begin{tabular}{lcccc}
\hline \multirow{2}{*}{ Treatment } & \multicolumn{2}{c}{ Grain yield $\left(\mathrm{t} \mathrm{ha}^{-1}\right)$} & \multicolumn{2}{c}{ Straw yield $\left(\mathrm{t} \mathrm{ha}^{-1}\right)$} \\
\cline { 2 - 5 } & Aus & Aman & Aus & Aman \\
\hline CT & 3.12 & 3.35 & 3.37 & 3.62 \\
ST & 3.03 & 3.65 & 3.03 & 3.77 \\
BP & 2.46 & 2.86 & 2.79 & 2.83 \\
ZT & 2.67 & 3.46 & 2.59 & 3.61 \\
CV $(\%)$ & 17.4 & 9.3 & 33.8 & 13.2 \\
LSD $_{0.05}$ & NS & NS & NS & NS \\
\hline
\end{tabular}

N.B. Values are the means of three replicates

Table 4. Economic productivity of direct seeded rice as affected by tillage options

\begin{tabular}{|c|c|c|c|c|c|c|c|c|}
\hline \multirow{2}{*}{$\begin{array}{l}\text { Tillage } \\
\text { options }\end{array}$} & \multicolumn{4}{|c|}{ Aus } & \multicolumn{4}{|c|}{ Aman } \\
\hline & $\begin{array}{c}\text { Input } \\
\text { cost } \\
\left(\mathrm{Tk} \mathrm{ha}^{-1}\right)\end{array}$ & $\begin{array}{c}\text { Gross } \\
\text { return } \\
\left(\mathrm{Tk} \mathrm{ha}^{-1}\right)\end{array}$ & $\begin{array}{c}\text { Gross } \\
\text { margin } \\
\left(\mathrm{Tk} \mathrm{ha}^{-1}\right)\end{array}$ & BCR & $\begin{array}{c}\text { Input } \\
\text { cost } \\
\left(\mathrm{Tk} \mathrm{ha}^{-1}\right)\end{array}$ & $\begin{array}{c}\text { Gross } \\
\text { return } \\
\left(\mathrm{Tk} \mathrm{ha}^{-1}\right)\end{array}$ & $\begin{array}{c}\text { Gross } \\
\text { margin } \\
\left(\mathrm{Tk} \mathrm{ha}^{-1}\right)\end{array}$ & $\mathrm{BCR}$ \\
\hline $\mathrm{CT}$ & 37,980 & 56,973 & 18,994 & 1.50 & 51,940 & 61,059 & 9,119 & 1.18 \\
\hline ST & 38,680 & 54,568 & 15,884 & 1.41 & 49,560 & 66,075 & 16,512 & 1.33 \\
\hline BP & 36,900 & 45,324 & 8,420 & 1.23 & 49,720 & 51,369 & 1,644 & 1.03 \\
\hline $\mathrm{ZT}$ & 37,310 & 47,785 & 10,477 & 1.28 & 49,460 & 62,665 & 13,202 & 1.27 \\
\hline
\end{tabular}

N.B. Values are the means of three replicates 


\subsection{Grain yield}

Table 3 shows the grain and straw yield of direct seeded rice in aus and aman season. During both seasons, rice and straw yield were similar across all treatments. In aus season, the highest grain yield was in CT followed by ST, ZT and BP. In aman season, the highest grain yield was obtained in ST, ZT, CT and BP. Minimum tillage had no effect on rice yields in either season.

\subsection{Economic analysis}

Table 4 included all inputs (fuel, labour, machine rental charge and other expenses) from land preparation to harvesting operation including transportation. Same amount of seed $\left(30 \mathrm{~kg} \mathrm{ha}^{-1}\right)$, and irrigation water was applied in all the plots. Tillage treatment showed significant effect on input cost but no significant effect on gross return, gross margin and benefit cost ratio (BCR) in both seasons. In aus season, gross margin was the highest in CT and the lowest in BP. Minimum tillage indicated the low gross margin compared to CT. Grain yield was higher in CT in aus season whereas higher in ST in aman season which led to increase gross return. In aman season, gross margin was the highest in ST and the lowest in BP. BCR was the highest in CT and $\mathrm{ST}$ in aus and aman season, respectively. BCR was the lowest in BP in both seasons.

Fuel consumption was influenced by a number of factors, including equipment type, speed of operation, depth of tillage, soil type, crop residue levels, soil moisture content, field shape and the number of tillage operations. Fuel consumption was higher in aman season than aus season which was due to aus rice was sown after harvesting potato and soil was loosened; whereas in aman season the soil surface was harder. The lowest fuel consumption in case of ST, compared to ZT may be due to negative draft and comparatively higher field capacity. Strip tillage saved $25-46 \%$ fuel seeding operation compared to CT. Similar result was obtained by Hossain et al. (2005). Fuel consumption was the highest in BP among the minimum tillage practices due to use of 24 tynes to till and throw the soil inward for bed formation indicating that more energy was needed to accomplish the task of bed shaping.

The highest cost in CT was due to more tillage and hand broadcasted seed and fertilizers, which increased the fuel and labour requirement. ST was the highest cost saving tillage technology for DSR establishment. Weeding cost was lower in aman season than aus season due to application of herbicide before seeding. Irrespective of the tillage treatment, tillering pattern followed increasing trend upto 55 and 95 DAS in aus and aman seasons, respectively and then it decreased gradually due to tiller mortality and leaf senescence. The yield attributes of rice crop showed that panicle intensity was higher in CT than other treatment but the compensating behavior of various yield components such as 1000 -grain weight, grain weight per panicle, or number of spikelets per panicle etc. resulted in similar grain yields for different tillage options in both seasons.

The number of passes and operation charges in terms of fuel consumption and task time were different in tillage options. In aus season, ST showed the highest input costs which was due to more weed infestation although it saved fuel, time and labour consumption in seeding operation. Grain yield was higher in CT and ST in aus and aman season, respectively which led to increase gross return. The insignificant difference in gross margins among the treatments could not be explained on the difference in their yields only as the net returns are affected by variable cost also. Minimum tillage indicated the low gross margin compared to $\mathrm{CT}$. The gross margin for CT was the highest due to the highest gross return compared with other tillage systems. In aus season, BCR was higher in all the tillage treatment as fertilizer was not applied in the field. Malhi et al. (1988) and Hoffman et al. (1999) reported that net economic returns were lower and little or no yield advantage for reduced tillage. This study also reflected the same trend. Profitability of establishing direct seeded rice in ST was higher than that of planting seeds in CT. Direct seeded rice established in BP was less profitable in High Barind Tract. 


\section{Conclusions}

Suitable planting machine is one of the important factors for timely sowing and successful crop establishment. Correct adjustment of planting machinery and accurate seed placement helped to improve seedling emergence. Seeds were not broken due to use of flute type seed metering device. Planter reduced seeding time, saved fuel and labour costs compared to conventional method. Yields were not significantly different under minimum tillage and CT. BP showed the lowest benefit-cost ratio compared to other tillage treatments. Strip tillage performed better than the other two minimum tillage methods compared to conventional method. Minimum tillage ensured the timeliness of operation in seeding operation. ST may be adapted to establish dry seeded rice in High Barind Tract.

\section{Acknowledgements}

This study was a part of the $\mathrm{PhD}$ research of the senior author. The authors acknowledge the funding support from NATP- Phase 1, Bangladesh Agricultural Research Council and ACIAR project.

\section{References}

Bell, M. A., Rickman, J., Castro, E., Clemeno, T. 1999. Better land preparation improves crop establishment and rice yields. Paper presented at Cambodia technical meeting, 11-13 May 1999, Cambodia-IRRIAustralia Project, Cambodia.

Bhuiyan, S. I., Sattar, M. A., Khan, M. A. K. 1995. Improving water use efficiency in rice irrigation through wet seeding. Irrigation Science, 16:1-8.

Gomez, K. A., Gomez, A. A. 1984, Statistical Procedures in Agricultural Research, New York, Chichester, Wiley, 2nd edition, 680 pp.

Haque, M. E., Bell, R. W., Islam, A. K. M. S., Sayre, K., Hossain, M. M. 2011. Versatile multi-crop planter for two-wheel tractors: an innovative option for smallholders. In: Gilkes R. J., Nattaporn, Prakongkep
(Eds.), 5th World Congress of Conservation Agriculture incorporating 3rd Farming Systems Design Conference. 26-29 September 2011 Brisbane, Australia, 102-103 pp.

Hobbs, P. R., Giri, G. S., Grace, P. 1997. Reduced and zero-tillage options for the establishment of wheat after rice in South Asia. International Maize and Wheat Improvement Centre. Rice-Wheat Consortium Paper No. 2. Mexico.

Hoffman, M. L., Buhler, D. D., Owen, D. K. 1999. Weed population and crop yield response to recommendations from weed control decision aid. Agronomy Journal, 91:386-392.

Hossain, M. I., Haque, M. E., Meisner, C. A., Sufian, M. A., Rahman, M. M. 2005. Strip Tillage Planting Method for Better Wheat Establishment. Journal of Science and Technology, 3:91-95.

Islam, A. K. M. S., Haque, M. E., Hossain, M. M., Saleque, M. A., Bell, R. W. 2010. Water and fuel saving technologies: Unpuddled bed and strip tillage for wet season rice cultivation in Bangladesh. In: Gilkes R. J., Nattaporn Prakongkep (Eds.). Division Symposium 3.2 Nutrient best management practices, Proceedings of 19th World Congress of Soil Science. Soil Solutions for a Changing World, Brisbane, Australia, 1-6 August 2010. International Union of Soil Science, Wageningen. The Netherlands. 169-172 pp.

Kathiresan, G., Manickam, G., Gnanamoorthy, P. 1997. Effect of timing of seeding and method of herbicide application on premonsoon sown semi-dry rice (Oryza sativa). Indian Journal of Agronomy, 42(4): 618-621.

Kukal, S. S., Aggarwal, G. C. 2002. Percolation losses of water in relation to puddling intensity and depth in a sandy loam rice (Oryza sativa) field. Agricultural Water Management, 57:49-59.

Malhi, S. S., Mumey, G., O'Sullivan, P. A., Harker, K. N. 1988. An economic 
comparison of barley production under zero and conventional tillage. Soil and Tillage Research, 11:159-166.

Pandey, S., Velasco, L. 2005. Trends in crop establishment methods in Asia and research issues. In: Rice is Life: Scientific Perspectives for the 21st Century, Proceedings of the World Rice Research Conference, 4-7 November 2004, Tsukuba, Japan, 178-181 pp.

Pathinayake, B., Nugaliyadde, L., Sandanayake, C. A. 1990. Direct seeding practices of rice in Sri Lanka. Paper presented in the International Rice Research Conference, Intl. Rice Res. Ins., Rural Development Administration, Seoul, Korea.

Rao, A. N., Johnson, D. E., Sivaprasad, B., Ladha, J. K., Mortimer, A. M. 2007. Weed management in direct-seeded rice. Advanced Agronomy, 93:153-255.

Rashid, M. H., Islam, M. S. 2007. Adaptation of climate change for sustainable development of Bangladesh Agriculture. Paper for the presentation in the $3^{\text {rd }}$ session of Technical Committee of Asian and Pacific Center for Agricultural Engineering and Machinery (APCAEM) on November 20-21, 2007, Beijing, China.

Rickman, J. F., Pyseth, M., Bunna, S., Sinath, P. 1999. Direct seeding of rice in Cambodia. Cambodia- IRRI-Australia Project, Phnom Penh, Cambodia. (Unpublished).

Saleh, A. F. M., Bhuiyan, S. I. 1995. Crop and rainwater management strategies for increasing productivity of rainfed lowland rice systems. Agricultural System, 49:259276.

Saleh, A. F. M., Mazid, M. A., Bhuiyan, S. I. 2000. Agrohydrologic and drought-risk analyses of rainfed cultivation in northwest Bangladesh. In: Tuong, T. P., Kam, S. P., Wade, L. J., Pandey, S., Bouman, B. A. M., Hardy, B., editors. Characterizing and understanding rainfed environments. Manila (Philippines): International Rice Research Institute. 233244 pp. 